\title{
The effect of Food Assistance on Adherence to Antiretroviral Therapy among HIV/AIDS Patients in Sofala Province, in Mozambique: A Retrospective Study
}

\author{
Mariana Posse ${ }^{1,2 *}$, Nyasha Tirivayi ${ }^{3}$, Unnati Rani Saha ${ }^{2}$ and Rob Baltussen ${ }^{2}$ \\ ${ }^{1}$ Faculty of Economics and Management, Catholic University of Mozambique, Beira, Mozambique \\ ${ }^{2}$ Department of Primary and Community Care, Radboud University Nijmegen Medical Centre, Nijmegen, The Netherlands \\ ${ }^{3}$ Maastricht Graduate School of Governance, UNU-MERIT, Maastricht University, The Netherlands
}

\begin{abstract}
Background: The availability of Antiretroviral Treatment (ART) has changed the course of HIVIAIDS, by transforming it into a chronic condition. However, important challenges remain in the management of HIVIAIDS These challenges are exacerbated by the fact that in resource limited settings, food insecurity and HIVIAIDS overlap. The aim of our study was to evaluate the effect of a food assistance program on adherence to ART in Sofala province, Mozambique.
\end{abstract}

Methods: In order to assess the effect of the food assistance program on adherence we used propensity score matching with difference in differences estimation. We compared food assistance recipients with controls. We measured adherence based on pill pick-up, a pharmacy adherence measure.

Results: During the food assistance programme, the adherence of food assistance recipients who received food assistance for a period of six and 12 months and non-food assistance recipients is not significantly different as the average impact is only $0.4 \%(p=0.94)$ and $-2.3 \%(p=0.73)$ respectively. For the period after food assistance had been terminated, adherence is still not significantly different between the two groups, as the average impact is $5.3 \%$ $(p=0.44)$ and $1.9 \%(p=0.65)$.

Conclusion: Our study suggests that food assistance provided to HIVIAIDS patients in Sofala province in Mozambique had no effect on their adherence to ART. Our results indicate that although efforts have been put forth to reduce food insecurity among HIVIAIDS patients, more should be done to ensure that these efforts really result in the improvement of adherence to ART.

Keywords: Antiretroviral treatment; Food insecurity; Food assistance; Adherence; Mozambique

\section{Introduction}

The availability of antiretroviral treatment (ART) has changed the course of HIV/AIDS, by transforming it into a chronic condition. ART has reduced the number of deaths and increased survival time. For example, in sub-Saharan Africa, the part of the world most impacted by HIV, the number of people dying of AIDS-related causes has declined by $32 \%$ between 2005 and 2011 [1]. However, important challenges remain in the management of HIV/AIDS. These include attempts to ensure that people in need of ART get it on time and take it at a regular basis for the rest of their lives. Taking medication at a regular and continuous basis is exhausting in any chronic condition, as it may lead to pill fatigue for example [2-4]. This challenge is exacerbated by the fact that in resource limited settings, food insecurity and HIV/AIDS overlap.

The vicious cycle of food insecurity and HIV/AIDS is well documented. HIV/AIDS reduces the capacity for food production or purchase, and this increases the vulnerability to HIV transmission by compromising the immuno status and by creating conditions for engagement in unprotected sex, involvement in intergenerational sex partners and transactional sex [5-8]. Food insecurity also impedes access to HIV treatment and care services since patients are reluctant to initiate ART because of the anxiety regarding being able to maintain consumption of sufficient food and a balanced diet [9-11]. Food insecurity also worsens clinical outcomes, particularly adherence [1215] which is a determinant factor for the virological success of ART, [16-19] and consequently of great importance in the prevention of HIV transmission [20].
In order to minimize food insecurity, food assistance interventions are being incorporated into ART programs [21]. Evidence in a range of low and middle income countries shows that this approach is effective as it is associated with improved food security, nutritional status, ART adherence, slow disease progression and probability of survival [22-26]. However, less is known about the impact of food assistance programs in Mozambique, where the prevalence of HIV/AIDS is $11.5 \%$ and more than a third of households (35\%) are highly vulnerable to food insecurity $[27,28]$. Therefore, the aim of our study was to evaluate the effect of a food assistance program on adherence to ART in Sofala province, Mozambique.

\section{Methods}

\section{Description of the food assistance program}

We evaluated the food assistance program as implemented by the

*Corresponding author: Mariana Posse, Radboud University Nijmegen Medical Centre, P.O Box 9101, 6500 HB Nijmegen, ELG 117, The Netherlands, Tel: +31-24-366-8161; Fax: +31-24-361-9561; E-mail: possemariana@gmail.com

Received February 18, 2013; Accepted March 22, 2013; Published March 27, 2013

Citation: Posse M, Tirivayi N, Saha UR, Baltussen R (2013) The effect of Food Assistance on Adherence to Antiretroviral Therapy among HIVIAIDS Patients in Sofala Province, in Mozambique: A Retrospective Study. J AIDS Clin Res 4: 198. doi:10.4172/2155-6113.1000198

Copyright: @ 2013 Posse M, et al. This is an open-access article distributed unde the terms of the Creative Commons Attribution License, which permits unrestricted use, distribution, and reproduction in any medium, provided the original author and source are credited. 
United Nations World Food Program (WFP), in collaboration with the Health Alliance International (HAI) and the Ministry of Health. HAI is a non-governmental organization that initiated operations in Mozambique in 1987. Its mission is to support the development of policies that foster social and economic equity for all, with a focus on public-sector health systems and a progressive realization of the right to health. In 2003, in partnership with the government of Mozambique, HAI began to support the implementation and expansion of ART for HIV/AIDS patients. It is within this partnership that HAI also collaborates with the WFP in providing food assistance for HIV/AIDS patients in Sofala Province.

The WFP is responsible for the provision of food while health centres are responsible for the identification of eligible patients and HAI is responsible for the distribution of food to patients. This intervention is provided to HIV/AIDS patients of all ages, including children, tuberculosis patients and pregnant and breast-feeding women enrolled in prevention of mother-to-child transmission (PMTCT) programs. The objective is to ensure patient nutritional recovery and treatment success.

The inclusion criteria in the food assistance program were body mass index (BMI) below $18.5 \mathrm{~kg} / \mathrm{m}^{2}$ earning no income or with income less than the monthly national minimum income and many dependents. Patients were identified before or after they started ART. They were first identified by a social worker, and their eligibility was later confirmed by a clinician. After being identified, patients received an identification card that entitled them to collect food at the distribution site, usually a warehouse or health facility. They received food assistance once per month for a period of three months, after which they were reassessed to determine whether their nutritional status had improved. If improved, patients were discharged from the program; otherwise, the patients remained in the program for an additional period of three to six months. Food assistance consisted of $10 \mathrm{~kg}$ of soya, $5 \mathrm{~kg}$ of cowpeas and $25 \mathrm{~kg}$ of maize.

\section{Study design}

This is a retrospective study where we extracted data from clinic and pharmacy records of HIV/AIDS patients for a period of 3 years (September 2007 to December 2010). From these records we collected information on the dates patients were scheduled to pick-up medication and the dates that they actually picked-up medication. In addition to that, we also collected their demographic information namely age, gender, occupation, educational level, marital status, number of household members, along with health information on CD4 counts, BMI, haemoglobin, opportunistic infections and WHO staging. We only collected, data of HIV/AIDS adult patients (18 years or older in September 2007) and excluded children, pregnant and breast-feeding women enrolled in PMTCT.

In order to assess the effect of the food assistance program on adherence, we compared patients who have received food assistance (food assistance recipients) from five districts in Sofala province (Beira, Dondo, Nhamatanda, Caia and Muanza) with similar patients, who did not receive food assistance (controls) from four districts in Zambezia province (Quelimane, Namacurra, Nicoadala and Mopeia). We choose Zambezia province, because this province like Sofala province, is also located in Mozambique central region and there was no food assistance program during that period. The food assistance recipients were selected by simple random sampling from a list of patients who had received food assistance between September 2008 to August 2010. The controls were randomly selected from the health facilities database based on the inclusion criteria used to select food assistance recipients. This study was approved by the Mozambican National Bioethics Committee.

\section{Variable description}

The main treatment variable was receipt of food assistance in the form of a food basket ration. Adherence was the primary outcome variable.

We measured adherence based on pill pick-up, a pharmacy adherence measure (PAM), which measures whether an individual picks-up all or a majority of their prescribed ART. PAMs are ideally suited to monitoring adherence because they are objective and can be easily derived from data routinely collected for other purposes, such as clinical care or drug supply management [29]. The underlying premise of this method is that if patients do not receive timely refills from the pharmacy, they are either missing doses (as measured by prolonged periods between refills) or not taking the medication at all. Adherence rates from pharmacy refill records are determined either by comparing actual to scheduled refill dates or by identifying "medication gaps," defined as periods of time during which the patient's supply of medication is assumed to have been exhausted [30]. The pharmacy refill approach has been validated as a measure of adherence since it has been shown to correlate significantly with clinical and virological outcomes [31-37].

We compared actual to scheduled refill dates and calculated medication gaps in terms of quantity and length. If a patient failed to pick-up medication on a scheduled date, we considered it a gap in pick-up and therefore a gap in medication for a certain number of days. Since most ART programs give additional pills for three days after the scheduled date, we only considered a gap in pick-up when the gap had a length greater than or equal to 3 days. If a patient picked-up ART on or before the scheduled refill date, we considered them to be on time. In Mozambique patients usually pick-up ART once every month. They may pick-up more than once in a month if for example; there are not enough pills at the health facility on the scheduled date.

In order to assess the effect of food assistance on adherence, we divided the whole period of analysis in three: before, during and after food assistance. For the control group, since they did not receive the food assistance, we divided the three periods based on the average length of each period of the food assistance recipients. As a measure of adherence, we calculated a score by dividing the number of medication gaps (times patients failed to pick-up ART) by the number of months in each period. By doing this, we standardized the periods since patients have different timing for each period. Accordingly, the higher the adherence score, the less adherent in the patient.

We also collected data on CD4, BMI, and haemoglobin for each period but did not include them in the analysis because there was not enough information for every month since they were not measured systematically at all health facilities included in the study.

\section{Data analysis}

We estimated the impact of food assistance using propensity score matching (PSM) with 'difference in differences' estimation. PSM allows us to match each food assistance recipient to a sample of similar non-food assistance recipient based on similar values of propensity scores. We used the available data to match the samples. We used the following characteristics, which we hypothesised to be associated with an increased propensity to receive food assistance and that satisfied the balancing condition of propensity score matching: gender, marital 
status, household size, ART initiation date and education level. We used the kernel estimator to match food assistance recipients to nonrecipient with the nearest estimated propensity score using the method of Leuven and Sianesi [38].

In order to analyse the change in adherence over time we combined PSM with difference in differences estimation to minimize selection bias and remove the effect of any unobserved time invariant differences between the treatment and comparison groups [22]. The difference in differences estimation compares the change on adherence over time for the food assistance recipients with the change on adherence over time for the control group by estimating the overall difference from the baseline and post differences between the two groups. We also categorized the patients based on the duration of receiving food assistance. In this case, the time periods were six and twelve months duration of receiving food assistance. In this study we estimated the difference between the period before food assistance (pre) and during the food assistance program (during) for both those on six and twelve months duration. We also estimated the difference between the period before (pre) and after food assistance was terminated (post).

\section{Results}

Table 1 shows that food assistance recipients (172) and controls

\begin{tabular}{|c|c|c|c|}
\hline Variables & $\begin{array}{l}\text { FA recipients } \\
(\mathrm{N}=172)\end{array}$ & $\begin{array}{l}\text { Controls } \\
(\mathrm{N}=185)\end{array}$ & P-value \\
\hline \multicolumn{4}{|l|}{ Gender n (\%) } \\
\hline Male & $38(22.09 \%)$ & $60(32.43 \%)$ & 0.029 \\
\hline Female & $134(77.91 \%)$ & $125(67.57 \%)$ & \\
\hline Age in years, mean (SD) & $38.52(9.06)$ & $36.61(10.20)$ & 0.014 \\
\hline \multicolumn{4}{|l|}{ Marital status n (\%) } \\
\hline Unmarried & $32(18.60 \%)$ & $67(36.22 \%)$ & 0.000 \\
\hline Married & $86(50 \%)$ & $96(51.89 \%)$ & 0.721 \\
\hline Widow & $50(29.07 \%)$ & $14(7.57 \%)$ & 0.000 \\
\hline \multicolumn{4}{|l|}{ Education levels n (\%) } \\
\hline No formal education & $82(47.67 \%)$ & $30(16.22 \%)$ & 0.000 \\
\hline Primary education & $76(44.19 \%)$ & $108(58.38 \%)$ & 0.007 \\
\hline Secondary education & $14(8.14 \%)$ & $47(25.41 \%)$ & 0.000 \\
\hline University & $0(0 \%)$ & $3(0.55 \%)$ & \\
\hline \multicolumn{4}{|l|}{ Occupation n (\%) } \\
\hline At work & $25(14.53 \%)$ & $96(51.89 \%)$ & 0.000 \\
\hline Not at work & $147(85.47 \%)$ & $89(48.11 \%)$ & \\
\hline \multicolumn{4}{|l|}{ Household size n (\%) } \\
\hline$\leq 4$ members & $74(43.02 \%)$ & $75(40.54 \%)$ & 0.635 \\
\hline$>4$ members & $98(56.98 \%)$ & $110(59.46 \%)$ & \\
\hline Missing & $13.63 \%$ & $8.94 \%$ & \\
\hline \multicolumn{4}{|c|}{ Months per period *, mean (SD) } \\
\hline Pre & $12.65(6.85)$ & $8.62(3.34)$ & \\
\hline During & $7.27(6.05)$ & $8.55(3.42)$ & \\
\hline Post & $10.15(5.85)$ & $8.50(3.51)$ & \\
\hline \multicolumn{4}{|l|}{ Gaps per period **, mean } \\
\hline Pre & 2.14 & 1.06 & 0.201 \\
\hline During & 1.2 & 1.1 & 0.03 \\
\hline Post & 1.8 & 1.05 & 0.001 \\
\hline
\end{tabular}

* Periods: Pre $=$ before food assistance, during $=$ during food assistance, post $=$ after food assistance,

${ }^{* *}$ Zero included in the mean, zero $=37 \%$ of all cases in the total sample -Standard deviations are in the parentheses

- FA- food assistance

Table 1: Summary statistics of food assistance recipients and controls.

\begin{tabular}{|c|c|c|c|}
\hline \multirow[b]{2}{*}{ By period } & \multicolumn{2}{|c|}{ Adherence score*, mean (SE) } & \multirow[b]{2}{*}{ P-value } \\
\hline & FA recipients $(\mathrm{N}=172)$ & Controls (N=185) & \\
\hline Pre & $0.153(0.012)$ & $0.131(0.013)$ & 0.201 \\
\hline During & $0.182(0.016)$ & $0.137(0.013)$ & 0.029 \\
\hline Post & $0.199(0.016)$ & $0.129(0.012)$ & 0.001 \\
\hline \multicolumn{4}{|c|}{ By socio-demographic characteristics ${ }^{* *}$} \\
\hline \multicolumn{4}{|l|}{ Gender } \\
\hline Male & $0.172(0.021)$ & $0.68(0.016)$ & 0.882 \\
\hline Female & $0.178(0.001)$ & $0.115(0.007)$ & 0.000 \\
\hline \multicolumn{4}{|l|}{ Age groups } \\
\hline$<30$ years old & $0.167(0.022)$ & $0.114(0.014)$ & 0.033 \\
\hline $30-39$ years old & $0.186(0.015)$ & $0.129(0.128)$ & 0.004 \\
\hline$>=40$ years old & $0.175(0.012)$ & $0.149(0.012)$ & 0.138 \\
\hline \multicolumn{4}{|l|}{ Marital status } \\
\hline Unmarried & $0.204(0.024)$ & $0.121(0.012)$ & 0.001 \\
\hline Married & $0.176(0.012)$ & $0.138(0.010)$ & 0.015 \\
\hline Widow & $0.144(0.014)$ & $0.131(0.023)$ & 0.641 \\
\hline \multicolumn{4}{|l|}{ Education levels } \\
\hline $\begin{array}{l}\text { No formal } \\
\text { education }\end{array}$ & $0.192(0.012)$ & $0.144(0.018)$ & 0.035 \\
\hline Primary education & $0.161(0.013)$ & $0.148(0.010)$ & 0.428 \\
\hline $\begin{array}{l}\text { Secondary } \\
\text { education }\end{array}$ & $0.182(0.039)$ & $0.087(0.010)$ & 0.001 \\
\hline University*** & - & - & \\
\hline \multicolumn{4}{|l|}{ Occupation } \\
\hline At work & $0.188(0.026)$ & $0.169(0.012)$ & 0.470 \\
\hline Not at work & $0.176(0.009)$ & $0.091(0.008)$ & 0.000 \\
\hline \multicolumn{4}{|l|}{ Household size } \\
\hline$<=4$ members & $0.178(0.013)$ & $0.116(0.011)$ & 0.000 \\
\hline Members $>4$ & $0.177(0.012)$ & $0.143(0.010)$ & 0.025 \\
\hline
\end{tabular}

* Adherence score=number of gaps/number of months in each period, zero included in the score.

**The adherence score for the socio-demographics is the mean for the three periods.

-Hypothesis tested against mean difference in adherence score between two groups!=0

- *** small number of cases

Table 2: T-test statistics of adherence score.

(185) did significantly differ by gender, age, marital status (unmarried and widow categories), educational level and occupation ( $\mathrm{p}<0.05$ for all of these comparisons) and not by household size and marital status (the married category). Food assistance recipients received food assistance for 7 months on average. Based on simple cross-section analysis, the mean adherence score of the food assistance recipients is significantly higher than the control group in the during and post period ( $\mathrm{p}=0.029$ and $\mathrm{p}<0.001$ respectively) (Table 2 ). This result suggests that food assistance recipients were less adherent to ART than the control group for the two periods. As for the mean adherence score by sociodemographic characteristics, it is significantly higher for the food assistance recipients with the following characteristics: female, less than 30 and 30-39 years old categories, unmarried and married categories, no formal education and secondary education categories, not at work and household size ( $<<0.05$ for all of these comparisons, Table 2). Otherwise, the adherence score for patients with other characteristics is reasonably similar for the two groups.

Using PSM, we generated a sample of matched food assistance recipients and controls. The total sample comprised 283 cases where 
133 were food assistance recipients and 150 were controls (on common support). To check if our matching was successful and of good quality, we tested for equality of means for each variable used in determining the propensity score and that showed that none of the variables were significantly different between food assistance recipients and controls (Table 3).

Table 4 shows the PSM estimates for adherence (plus difference in differences estimation). During the food assistance programme, the adherence of recipients who participated in the programme for six months is not significantly different from the non-recipients as the average impact is only $0.4 \%(\mathrm{p}=0.94)$. For those who had been on the programme for 12 months, the average impact is $-2.3 \%$ and not significantly different from the non-recipients $(p=0.73)$. After food assistance has been terminated, there is some improvement in the average adherence levels, however it remains non-significant. The average impact for those who had been on the food assistance programme for six months is $5.3 \%(\mathrm{p}=0.44)$, while for those who had been on the programme for 12 months the impact on adherence is $1.9 \%$ $(\mathrm{p}=0.65)$.

\section{Discussion}

Our analysis suggests that food assistance provided to HIV/AIDS patients in Sofala province in Mozambique had no effect on their adherence to ART, measured here as the number of times patients failed to collect medication; whereby patients received food assistance for 7 months on average.

Our results contradict results from other studies that have found an effect of food assistance in adherence to ART in other resource limited settings. For example, studies in Niger and Zambia [24-26], evaluated the effect of food assistance and found a positive effect on adherence to ART. A study in Haiti [23], found that food assistance improved the timely attendance of monthly clinic visits.

Yet our results should be interpreted with caution. Food insecurity is documented as one of the barriers to adherence to ART [15,39-43] and as such it is unexpected that food supplementation would not improve adherence. We hypothesize that the following factors may explain the

\begin{tabular}{|l|c|c|c|c|}
\hline Variable & \multicolumn{2}{|c|}{ Mean } & t-statistic & p-value \\
\hline & $\begin{array}{c}\text { FA recipients } \\
\text { (N=133) }\end{array}$ & $\begin{array}{c}\text { Controls } \\
(\mathbf{N}=150)\end{array}$ & & \\
\hline Age (in years) & 37.90 & 36.89 & 0.90 & 0.37 \\
\hline Female & 0.75 & 0.76 & -0.22 & 0.83 \\
\hline Not married & 0.20 & 0.22 & -0.25 & 0.80 \\
\hline Widow & 0.22 & 0.23 & -0.18 & 0.86 \\
\hline No of household members & 4.99 & 5.16 & -0.56 & 0.58 \\
\hline Date of ARV initiation & 20 October 2007 & 2 December 2007 & -1.00 & 0.32 \\
\hline Primary education & 0.49 & 0.42 & 1.06 & 0.29 \\
\hline Secondary education & 0.10 & 0.12 & -0.69 & 0.49 \\
\hline
\end{tabular}

Table 3: Propensity score estimation: mean differences of covariates after matching.

\begin{tabular}{|l|c|c|c|c|}
\hline During FA & FA recipients (n) & Controls (n) & $\begin{array}{c}\text { Difference in } \\
\text { Difference }\end{array}$ & P-value \\
\hline Six month duration & $0.048(55)$ & $0.044(60)$ & $\mathbf{0 . 0 0 4}$ & 0.94 \\
\hline 12 month duration & $0.021(7)$ & $0.044(81)$ & $\mathbf{- 0 . 0 2 3}$ & 0.73 \\
\hline After FA & & & & \\
\hline Six month duration & $0.071(56)$ & $0.018(54)$ & $\mathbf{0 . 0 5 3}$ & 0.44 \\
\hline 12 month duration & $0.047(52)$ & $0.066(118)$ & $\mathbf{0 . 0 1 9}$ & 0.65 \\
\hline
\end{tabular}

Table 4: Propensity score matching results on adherence (difference in differences). unobserved effect of this food program on adherence to ART. First, we did not evaluate the implementation of the food assistance program, and there may be aspects intrinsic to the program that may have affected its ability to produce an effect on patients' adherence to ART. For example, in our evaluation of patient satisfaction with the program, they mentioned that they were not satisfied with the enrolment period in the program. Therefore, future research evaluating the effect of food assistance programs could also assess the role of program design and implementation in order to aid in the interpretation of results.

Second, it may be that the food assistance program may have improved patients nutritional status but not their ability to collect medication. We expect other reasons than food insecurity to have affected access to medication as shown by other studies [44]. Moreover, since food supplies are often housed separately from the health facilities, patients may have faced transport difficulties [10,45-48], especially when timing of food distributions does not match with health facility visits. The placement of food aid at the health facilities and the use of transport vouchers can incentivize pill pick-up [25,26,49].

Finally, since the adherence measure we used is based on pill pickup, and does not account for medication obtained outside the health facility, it could be that patients got their medication elsewhere, and therefore did not show up at the health facility to collect medication. However, getting medication outside the health facilities where a patient is registered is unlikely in Mozambique.

Our study has several limitations. We used retrospective data, which does face challenges of completeness. Registration is not always accurate and this may have led to an apparent high number of gaps in medication collection, while in reality patients came to collect them. Another consequence related to the limitation in the completeness of data is that we were unable to correlate adherence to ART with other clinical outcomes such as BMI, CD4 and opportunistic infections to better interpret the results as performed in other studies [32-36,50]. Correlating adherence with clinical outcomes is important because there is no guarantee that all ART pills retrieved at the pharmacy are actually taken by patients.

The fact that this was a retrospective study and not prospectively randomised, may have been another limitation. However, we used a quasi-experimental design by performing PSM with difference in differences estimates which allowed us to match each food assistance recipient to a sample of similar non-food assistance recipient and removed the effect of unobserved time invariant differences between both groups. Despite the limitations, by using an objective and not expensive adherence measure easily calculated from information routinely available in medical and pharmacy records, our results could be generalized to other settings.

In conclusion, our study suggests that food assistance provided to HIV/AIDS patients in Sofala province in Mozambique had no effect on their adherence to ART. Our results indicate that although efforts have been put forth to reduce food insecurity among HIV/AIDS patients, more should be done to ensure that these efforts really result in the improvement of adherence to ART.

\section{Acknowledgements}

We would like to thank the World Food Program, Health Alliance International, the Sofala Health Provincial Directorate and Health Facilities and the Beira Centre for Operational Research (CIOB) for their cooperation in the implementation of the study. We would also like to thank Hans Bor for his statistical assistance.

Funding for the study was provided by NUFFIC (The Netherlands Organization for International Cooperation in Higher Education) under the Research and 
Citation: Posse M, Tirivayi N, Saha UR, Baltussen R (2013) The effect of Food Assistance on Adherence to Antiretroviral Therapy among HIV/AIDS Patients in Sofala Province, in Mozambique: A Retrospective Study. J AIDS Clin Res 4: 198. doi:10.4172/2155-6113.1000198

Education program on HIV/AIDS in Mozambique (NUFFIC, NPT/MOZ/083) and the Radboud University Nijmegen Medical Centre. The Beira Centre for Operational Research (CIOB) facilitated office space for Mariana Posse. NUFFIC, CIOB and the intervention implementing organizations had no role in the study design, data collection, analysis, or preparation of the manuscript.

\section{References}

\section{UNAIDS (2012) World AIDS Day Report.}

2. Nachega JB, Uthman OA, Anderson J, Peltzer K, Wampold S, et al. (2012) Adherence to antiretroviral therapy during and after pregnancy in low-income, middle-income, and high-income countries: a systematic review and metaanalysis. AIDS 26: 2039-2052.

3. Sow PG, Toure K, Coume M, Dia AT, Traore I (2012) Predictors of ART adherence among HIV infected individuals in Dakar, Senegal. Journal of Medicine and Medical Science 3: 212-216.

4. Li L, Ji G, Ding Y, Tian J, Lee A (2012) Perceived burden in adherence of antiretroviral treatment in rural China. AIDS Care 24: 502-508.

5. Weiser SD, Leiter K, Bangsberg DR, Butler LM, Percy-de Korte F, et al. (2007) Food insufficiency is associated with high-risk sexual behavior among women in Botswana and Swaziland. PLoS Med 4: 1589-1597.

6. Miller CL, Bangsberg DR, Tuller DM, Senkungu J, Kawuma A, et al. (2011) Food Insecurity and Sexual Risk in an HIV Endemic Community in Uganda. AIDS Behav 15: 1512-1519.

7. Oyefara JL (2007) Food insecurity, HIVIAIDS pandemic and sexual behaviour of female commercial sex workers in Lagos metropolis, Nigeria. SAHARA J 4 626-635

8. Tsai AC, Hung KJ, Weiser SD (2012) Is food insecurity associated with HIV risk? Cross-sectional evidence from sexually active women in Brazil. PLoS Med 9: e1001203.

9. Mshana GH, Wamoyi J, Busza J, Zaba B, Changalucha J, et al. (2006) Barriers to accessing antiretroviral therapy in Kisesa, Tanzania: a qualitative study of early rural referrals to the national program. AIDS Patient Care STDS 20: 649657.

10. Posse M, Baltussen R (2009) Barriers to access to antiretroviral treatment in Mozambique, as perceived by patients and health workers in urban and rural settings. AIDS Patient Care STDS 23: 867-875.

11. Weiser SD, Tsai AC, Gupta R, Frongillo EA, Kawuma A, et al. (2012) Food insecurity is associated with morbidity and patterns of healthcare utilization among HIV-infected individuals in a resource-poor setting. AIDS 26: 67-75.

12. Wang EA, McGinnis KA, Fiellin DA, Goulet JL, Bryant K, et al. (2011) Food insecurity is associated with poor virologic response among HIV-infected patients receiving antiretroviral medications. J Gen Intern Med 26: 1012-1018.

13. Unge C, Johansson A, Zachariah R, Some D, Van Engelgem I, et al. (2008) Reasons for unsatisfactory acceptance of antiretroviral treatment in the urban Kibera slum, Kenya. AIDS Care 20: 146-149.

14. Sanjobo N, Frich JC, Fretheim A (2008) Barriers and facilitators to patients adherence to antiretroviral treatment in Zambia: a qualitative study. SAHARA J 5: 136-143

15. Au JT, Kayitenkore K, Shutes E, Karita E, Peters PJ, et al. (2006) Access to adequate nutrition is a major potential obstacle to antiretroviral adherence among HIV-infected individuals in Rwanda. AIDS 20: 2116-2118.

16. El-Khatib Z, Ekstrom AM, Coovadia A, Abrams EJ, Petzold M, et al. (2011) Adherence and virologic suppression during the first 24 weeks on antiretroviral therapy among women in Johannesburg, South Africa - a prospective cohort study. BMC Public Health 11: 88.

17. Anema A, Vogenthaler N, Frongillo EA, Kadiyala S, Weiser SD (2009) Food insecurity and HIVIAIDS: current knowledge, gaps, and research priorities. Curr HIVIAIDS Rep 6: 224-231.

18. Weiser SD, Young SL, Cohen CR, Kushel MB, Tsai AC, et al. (2011) Conceptual framework for understanding the bidirectional links between food insecurity and HIVIAIDS. Am J Clin Nutr 94: 1729S-1739S.

19. Gross R, Yip B, Lo Re V 3rd, Wood E, Alexander CS, et al. (2006) A simple dynamic measure of antiretroviral therapy adherence predicts failure to maintain HIV-1 suppression. J Infect Dis 194: 1108-1114

20. Donnell D, Baeten JM, Kiarie J, Thomas KK, Stevens W, et al. (2010)
Heterosexual HIV-1 transmission after initiation of antiretroviral therapy: prospective cohort analysis. Lancet 375: 2092-2098.

21. Anema A, Zhang W, Wu Y, Elul B, Weiser SD, et al. (2012) Availability of nutritional support services in HIV care and treatment sites in sub-Saharan African countries. Public Health Nutr 15: 938-947.

22. Rawat R, Kadiyala S, McNamara PE (2010) The impact of food assistance on weight gain and disease progression among HIV-infected individuals accessing AIDS care and treatment services in Uganda. BMC Public Health 10: 316.

23. Ivers LC, Chang Y, Gregory Jerome J, Freedberg KA (2010) Food assistance is associated with improved body mass index, food security and attendance at clinic in an HIV program in central Haiti: a prospective observational cohort study. AIDS Res Ther 7: 33

24. Serrano C, Laporte R, Ide M, Nouhou Y, de Truchis P, et al. (2010) Family nutritional support improves survival, immune restoration and adherence in HIV patients receiving ART in developing country. Asia Pac J Clin Nutr 19: 68-75.

25. Cantrell RA, Sinkala M, Megazinni K, Lawson-Marriott S, Washington S, et al. (2008) A pilot study of food supplementation to improve adherence to antiretroviral therapy among food-insecure adults in Lusaka, Zambia. J Acquir Immune Defic Syndr 49: 190-195

26. Tirivayi N, Koethe JR, Groot W (2012) Clinic-Based Food Assistance is Associated with Increased Medication Adherence among HIV-Infected Adults on Long-Term Antiretroviral Therapy in Zambia. J AIDS Clin Res 3: 171

27. National AIDS Council (2012) Global AIDS Response Progress Report Mozambique.

28. Food and Agriculture Organization of the United Nations (FAO) (2011) Nutrition Country Profile. Republic of Mozambique.

29. McMahon JH, Jordan MR, Kelley K, Bertagnolio S, Hong SY, et al. (2011) Pharmacy adherence measures to assess adherence to antiretroviral therapy: review of the literature and implications for treatment monitoring. Clin Infect Dis 52: 493-506.

30. Berg KM, Arnsten JH (2006) Practical and conceptual challenges in measuring antiretroviral adherence. J Acquir Immune Defic Syndr 43 Suppl 1: S79-S87.

31. El-Khatib Z, Katzenstein D, Marrone G, Laher F, Mohapi L, et al. (2011) Adherence to drug-refill is a useful early warning indicator of virologic and immunologic failure among HIV patients on first-line ART in South Africa. PLoS One 6: e17518.

32. Grossberg R, Gross R (2007) Use of Pharmacy Refill Data as a Measure of Antiretroviral Adherence. Current HIVIAIDS Reports 4: 187-191.

33. Bisson GP, Gross R, Bellamy S, Chittams J, Hislop M, et al. (2008) Pharmacy refill adherence compared with CD4 count changes for monitoring HIV-infected adults on antiretroviral therapy. PLoS Med 5: e109.

34. Rougemont M, Stoll BE, Elia N, Ngang P (2009) Antiretroviral treatment adherence and its determinants in Sub-Saharan Africa: a prospective study at Yaounde Central Hospital, Cameroon. AIDS Res Ther 6: 21.

35. Ross-Degnan D, Pierre-Jacques M, Zhang F, Tadeg H, Gitau L, et al. (2010) Measuring adherence to antiretroviral treatment in resource-poor settings: the clinical validity of key indicators. BMC Health Serv Res 10: 42.

36. Kunutsor S, Walley J, Katabira E, Muchuro S, Balidawa H, et al. (2010) Clinic Attendance for Medication Refills and Medication Adherence amongst an Antiretroviral Treatment Cohort in Uganda: A Prospective Study. AIDS Res Treat 2010: 872396

37. Chalker JC, Andualem T, Gitau LN, Ntaganira J, Obua C, et al (2010) Measuring adherence to antiretroviral treatment in resource-poor settings: the feasibility of collecting routine data for key indicators. BMC Health Serv Res 10: 43.

38. Leuven E, Sianesi B (2003) psmatch2: Stata module to perform full Mahalanobis and propensity score matching, common support graphing and covariate imbalance testing".

39. Lyimo RA, de Bruin M, van den Boogaard J, Hospers HJ, van der Ven A, et al. (2012) Determinants of antiretroviral therapy adherence in northern Tanzania: a comprehensive picture from the patient perspective. BMC Public Health 12 716 .

40. Groh K, Audet CM, Baptista A, Sidat M, Vergara A, et al. (2011) Barriers to antiretroviral therapy adherence in rural Mozambique. BMC Public Health 11: 650. 
Citation: Posse M, Tirivayi N, Saha UR, Baltussen R (2013) The effect of Food Assistance on Adherence to Antiretroviral Therapy among HIV/AIDS Patients in Sofala Province, in Mozambique: A Retrospective Study. J AIDS Clin Res 4: 198. doi:10.4172/2155-6113.1000198

41. Coetzee B, Kagee A, Vermeulen N (2011) Structural barriers to adherence to antiretroviral therapy in a resource-constrained setting: the perspectives of health care providers. AIDS Care 23: 146-151.

42. Franke MF, Murray MB, Muñoz M, Hernández-Díaz S, Sebastián JL, et al. (2011) Food insufficiency is a risk factor for suboptimal antiretroviral therapy adherence among HIV-infected adults in urban Peru. AIDS Behav 15: 14831489.

43. Weiser SD, Tuller DM, Frongillo EA, Senkungu J, Mukiibi N, et al. (2010) Food insecurity as a barrier to sustained antiretroviral therapy adherence in Uganda. PLoS One 5: e10340.

44. Govindasamy D, Ford N, Kranzer K (2012) Risk factors, barriers and facilitators for linkage to antiretroviral therapy care: a systematic review. AIDS 26: 2059 2067.

45. Wasti SP, van Teijlingen E, Simkhada P, Randall J, Baxter S, et al. (2012) Factors influencing adherence to antiretroviral treatment in Asian developing countries: a systematic review. Trop Med Int Health 17: 71-81.

46. Kagee A, Remien RH, Berkman A, Hoffman S, Campos L, et al. (2011) Structural barriers to ART adherence in Southern Africa: Challenges and potential ways forward. Glob Public Health 6: 83-97.

47. Biadgilign S, Deribew A, Amberbir A, Deribe K (2009) Barriers and facilitators to antiretroviral medication adherence among HIV-infected paediatric patients in Ethiopia: A qualitative study. SAHARA J 6: 148-154.

48. Amuron B, Namara G, Birungi J, Nabiryo C, Levin J, et al. (2009) Mortality and loss-to-follow-up during the pre-treatment period in an antiretroviral therapy programme under normal health service conditions in Uganda. BMC Public Health 9: 290.

49. Emenyonu N, Muyindike W, Habyarimana J, Pops-Eleches C, Thirumurthy $\mathrm{H}$, et al. (2010) Cash transfers to cover clinic transportation costs improve adherence and retention in care in a HIV treatment program in rural Uganda. 17th Conference on Retroviruses and Opportunistic Infections, San Francisco, CA.

50. Nachega JB, Hislop M, Dowdy DW, Lo M, Omer SB, et al. (2006) Adherence to highly active antiretroviral therapy assessed by pharmacy claims predicts survival in HIV-infected South African adults. J Acquir Immune Defic Syndr 43 78-84. 